\title{
ARTICLE
}

Received 13 Jan 2014 | Accepted 5 Aug 2014 | Published 11 Sep $2014 \quad$ DOl: 10.1038/ncomms5912

\section{Persistence of pressure patterns over North America and the North Pacific since AD 1500}

\author{
Erika K. Wise $^{1} \&$ Matthew P. Dannenberg ${ }^{1}$
}

Changes in moisture delivery to western North America are largely controlled by interrelated, synoptic-scale atmospheric pressure patterns. Long-term records of upper-atmosphere pressure and related circulation patterns are needed to assess potential drivers of past severe droughts and evaluate how future climate changes may impact hydroclimatic systems. Here we develop a tree-ring-based climate field reconstruction of cool-season $500 \mathrm{hPa}$ geopotential height on a $2^{\circ} \times 2^{\circ}$ grid over North America and the North Pacific to AD 1500 and examine the frequency and persistence of preinstrumental atmospheric pressure patterns using Self-Organizing Maps. Our results show extended time periods dominated by a set of persistent upper-air pressure patterns, providing insight into the atmospheric conditions leading to periods of sustained drought and pluvial periods in the preinstrumental past. A striking shift from meridional to zonal flow occurred at the end of the Little Ice Age and was sustained for several decades.

\footnotetext{
${ }^{1}$ Department of Geography, University of North Carolina at Chapel Hill, Chapel Hill, North Carolina 27599, USA. Correspondence and requests for materials should be addressed to E.K.W. (email: ekwise@email.unc.edu).
} 
T he position of the mid-latitude storm track, which represents the primary large-scale moisture-delivery pathway to North America, is closely connected to the strength and position of upper-atmosphere pressure features such as the Pacific subtropical high and the Aleutian low ${ }^{1}$. Changes in these synoptic pressure features have been linked to global-scale oscillations in coupled ocean-atmosphere systems (particularly the El Niño-Southern Oscillation (ENSO) system) ${ }^{2,3}$ and to Northern Hemisphere wave-train disturbances such as those described by the Pacific North American (PNA) pattern ${ }^{4}$. Shifts in the dominance of certain synoptic-scale atmospheric features have occurred over the instrumental period and influenced drought and flood regimes in western North America, including the early 20th century pluvial period and the devastating droughts of the 1930s and 1950s (ref. 5).

Records from tree rings and other paleoclimate proxies have provided insight into the range of variability in the hydroclimatic system beyond the relatively short instrumental record. One of the most important findings in water-limited western North America is that there have been periods of severe and sustained drought in the preinstrumental past exceeding known droughts from the instrumental record ${ }^{6}$. The cause of these droughts is thought to be sustained shifts in moisture delivery processes linked to changes in ocean-atmosphere systems, particularly ENSO $^{6}$. While many droughts are synchronous with La Niña events, others are not and require additional explanation such as the inclusion of North Pacific influences ${ }^{3}$.

Long-term pressure data derived from the tree-ring record can be used to extend our understanding of these shifts in moisturedelivery processes by allowing an assessment of the frequency and persistence of certain circulation patterns and their variability through time. Although there have been numerous reconstructions of teleconnection indices, relatively few studies have engaged in synoptic dendroclimatology as a way to link tree growth with large-scale climate delivery systems through a focus on pressure patterns ${ }^{7}$. Pressure itself does not limit tree growth, but seasonal pressure anomalies reflect large-scale, persistent perturbations in climate ${ }^{8}$ and are associated with the suite of variables that do control growth, including temperature, moisture, wind and cloud $\operatorname{cover}^{7,9}$. Past research comparing pressure data with tree-ring growth over the instrumental time period found that variations in pressure accounted for more variance in growth than did single climate variables such as temperature or precipitation, likely due to the multivariate climate controls on growth that are reflected in pressure fields ${ }^{7}$.
Pressure anomalies in the upper atmosphere can persist for years to decades and influence temperature, precipitation and storm tracks over North America ${ }^{9}$. Extending the record of these anomalies would allow for a better understanding of the drivers of past climate conditions. This has become particularly important for future climate change forecasting and planning, as ongoing changes in atmospheric circulation due to anthropogenic forcing have already been identified ${ }^{9}$. Here, we use regularized expectation maximization with ridge regression (RegEMridge $)^{10,11}$ to develop a spatial reconstruction of cool-season, $500 \mathrm{hPa}$ geopotential height (GPH) anomalies since AD 1500. We then investigate dominant synoptic climate patterns embedded within this reconstruction using Self-Organizing Maps (SOM). Our findings, which show extended time periods dominated by a set of persistent upper-air pressure patterns over the 511-year record, provide insight into the atmospheric conditions associated with distinctive terrestrial hydroclimate conditions in the preinstrumental past and suggest that the end of the Little Ice Age (LIA) was marked by an abrupt transition from strong meridional to zonal flow.

\section{Results}

Reconstructed atmospheric pressure. RegEM-ridge ${ }^{10,11}$, which utilizes covariance within and between the instrumental and proxy data to iteratively impute missing values in the full data matrix, has been applied in previous paleoclimate reconstructions $^{12,13}$ and has demonstrated skill with the datasets used in this study ${ }^{14}$. Our reconstruction, developed using tree-ring data from the International Tree-Ring Data Bank (ITRDB; Fig. 1 and Methods) and NCEP/NCAR Twentieth Century Reanalysis V2 climate data (20CR2) provides coolseason (October-March), $500 \mathrm{hPa}$ GPH anomalies back to AD 1500 on a $2^{\circ} \times 2^{\circ}$ grid over western North America and the northeastern Pacific Ocean. The $500 \mathrm{hPa}$ level has been widely used in the study of atmospheric circulation due the strength of teleconnection patterns at this height ${ }^{4}$. The October-March cool season is a time of pronounced teleconnection influence ${ }^{4}$ and a vital period for moisture delivery to western North America ${ }^{1,2}$. The seasonal climate signal reflected in tree growth varies depending on geographic location, elevation and species ${ }^{15}$. Coolseason climate conditions have a strong influence on tree growth across a variety of climate zones due to effects on processes such as cambial activation, root mortality, xylem embolisms and soil moisture recharge ${ }^{15-17}$. The GPH reconstruction model demonstrates skill throughout the spatial domain as assessed by standard climate field reconstruction validation metrics (Fig. 2).

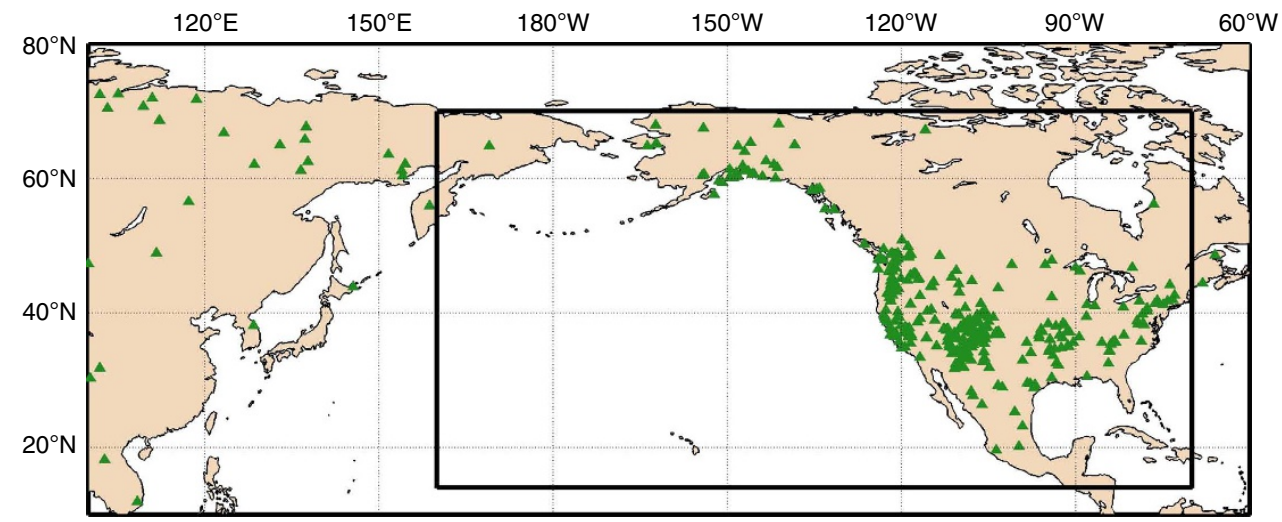

Figure 1 | Spatial domain of GPH reconstruction and tree-ring site locations. Cool-season (October-March) $500 \mathrm{hPa}$ GPH anomalies were reconstructed on a $2^{\circ} \times 2^{\circ}$ grid over $14^{\circ} \mathrm{N}-70^{\circ} \mathrm{N}$ latitude and $160^{\circ} \mathrm{E}-70^{\circ} \mathrm{W}$ longitude (inner box) using ITRDB tree-ring sites correlated with GPH at a 0.001 significance level (green triangles) within the spatial domain bounded by $10^{\circ} \mathrm{N}-80^{\circ} \mathrm{N}$ latitude and $100^{\circ} \mathrm{E}-60^{\circ} \mathrm{W}$ longitude (outer box). 
a

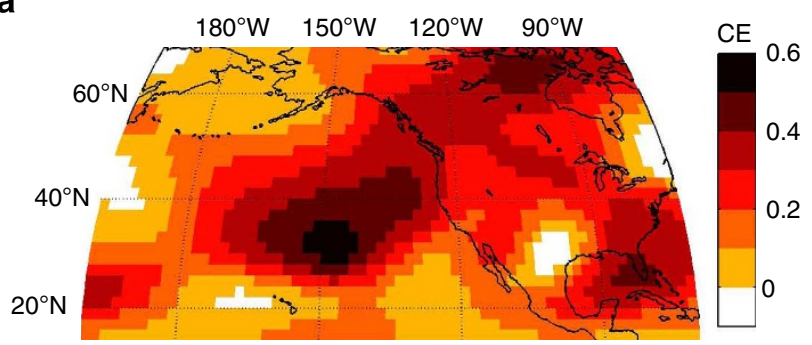

b

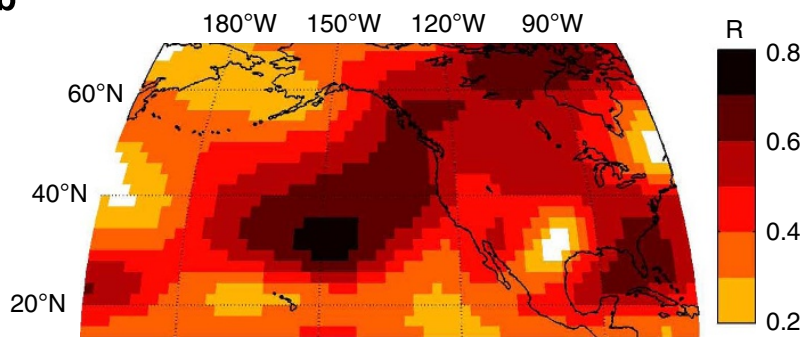

C

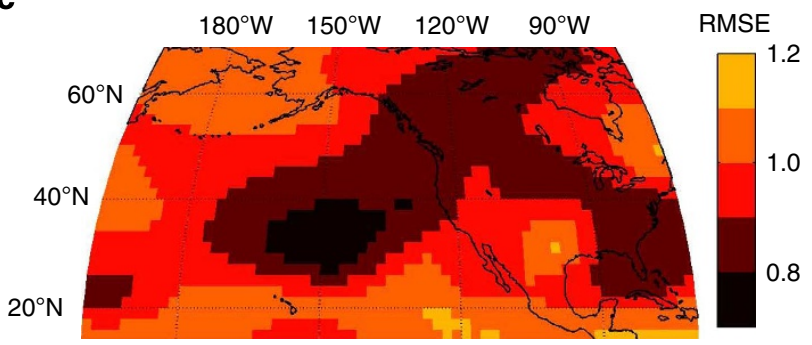

Figure 2 | Spatial validation metrics for the RegEM-ridge reconstruction model. (a) coefficient of efficiency (CE), where values of CE can range from $-\infty$ to 1 and any CE greater than zero (shaded areas) indicates predictive skill. (b) Pearson correlation coefficient $(R)$ between the predicted and observed data; all shaded grid cells are significant at or above the $95 \%$ confidence level. (c) root mean squared error (RMSE). Metrics of model skill were assessed using a leave-decade-out cross-validation approach over the 1872-1971 time period.

Dominant synoptic climate patterns. SOM, an unsupervised, artificial neural network approach ${ }^{18,19}$, was applied to the reconstructed data to analyse the frequency and persistence of atmospheric pressure patterns and their changes through time. The SOM technique organized the 511-year GPH dataset into a two-dimensional $3 \times 5$ grid topology of statistically distinguishable synoptic circulation patterns, or 'nodes' (Fig. 3). Each of the 15 nodes represents a theoretical GPH pattern (rather than a composite of cases) based on the underlying data distribution within the input dataset. The primary differences among the GPH anomaly patterns (Fig. 3) are the strength and position of the Aleutian low and the placement and degree of troughing or ridging over North America. Within the SOM organizational structure, there is a transition across columns 1 through 5 from a weak Aleutian low to a deep Aleutian low and from troughing over North America to ridging. Down through the three rows, there is a transition in strength and position of $\mathrm{GPH}$ anomalies, from patterns with relatively weak anomalies in row 1 to stronger anomalies in row 3 .

These differences in mean upper-air pressure would result in changes to regional atmospheric flow patterns and storm-track trajectories. Overall, the weaker anomalies in row 1 suggest zonal flow patterns, transitioning to stronger meridional flow patterns through rows 2 and 3. Between rows 1 and 3, the ridge-trough pattern characteristic of PNA + (columns 4 and 5) shifts to the west, while the reverse pattern (columns 1 and 2) shifts to the east (Fig. 3). Changes in the position of the trough and ridge axes, which alter the spatial distribution of temperature and precipitation $^{5}$, have important implications for terrestrial climate conditions.

The transition in anomaly patterns across columns suggests a shift in the westerly storm track from more northerly flow in column 1 to increasingly southerly flow in column 5 (Fig. 3). Columns 1 and 5 are strongly indicative of La Niña and El Niño conditions, respectively. On the basis of the instrumental record of ENSO, the La Niña-type GPH anomaly patterns (column 1) would likely be associated with a westward retraction of the East Asian jet stream and a bifurcated or northerly shift of the storm track across North America, while the El Niño-like patterns (column 5) would be associated with an enhanced East Asian jet stream and a storm track shifted south. Columns 2-4 represent transitions between these two extremes, including ENSO-neutral conditions.

Circulation changes through time. The placement of archetypal nodes that span the continuum of data allow SOM to capture non-linear aspects of the data and to operate without needing to conform to a specific predefined data distribution ${ }^{18,19}$. This is particularly relevant when dealing with paleoclimate, when dominant patterns may have differed from the instrumental period; however, there is still the potential for 'no analog' paleoclimate conditions that lie outside the instrumental data domain ${ }^{20}$. Each input value to the SOM (here, the yearly spatial grids of cool-season GPH anomalies) maps to the node with the lowest error, allowing analysis of frequency of occurrence through time ${ }^{19}$. The overall frequency of pattern occurrence is highly variable and ranges from 3.5 to $11.5 \%$; three of the 15 nodes have frequencies that are significantly higher or lower than the expected value of $6.7 \%$ (Fig. 3). Over the 511-year record, there have been sustained shifts in the prevalence of pressure patterns over time (Figs 4 and 5). To emphasize changes across the SOM two-dimensional structure, we calculated the number of occurrences of each node (grouped by row and column) within 25-year moving windows, with statistical significance tested using a series of first-order Markov chain simulations ${ }^{21}$. Node assignments were further evaluated through comparison with an ensemble of plausible preinstrumental GPH fields generated using a suite of synthetic tree-ring records in a pseudoproxy experiment (PPE) ${ }^{22}$ (Figs 4 and 5 and Supplementary Tables 1 and 2). The most dramatic GPH pattern shift occurred following the end of the LIA ( $\sim$ AD1450-1850), when a 40-year period (1810s to 1850s) dominated by meridional flow (row 3) ended with a sharp transition to zonal flow (row 1) that was sustained for approximately 50 years (1860s to 1910s; Fig. 5). Beginning in the early 1900 s, there was a slow transition back to persistent meridional flow (row 3).

\section{Discussion}

The end of the LIA in the mid-1800s has been identified as a period of fundamental change in atmospheric circulation ${ }^{23,24}$, and major climatic shifts during this period have been documented in ice cores, lake cores and tree rings ${ }^{25}$. This change has been attributed to a major reorganization of Pacific Ocean circulation ${ }^{23}$, which may be related to an increased connection between the northern and tropical Pacific after the mid-1800s (ref. 26) or between the North Pacific and North Atlantic Oceans ${ }^{24}$. Multiple studies have indicated that the end of the LIA corresponded to reduced North Pacific decadal forcing $9,23,27$. The end of the LIA may also represent a shift from 

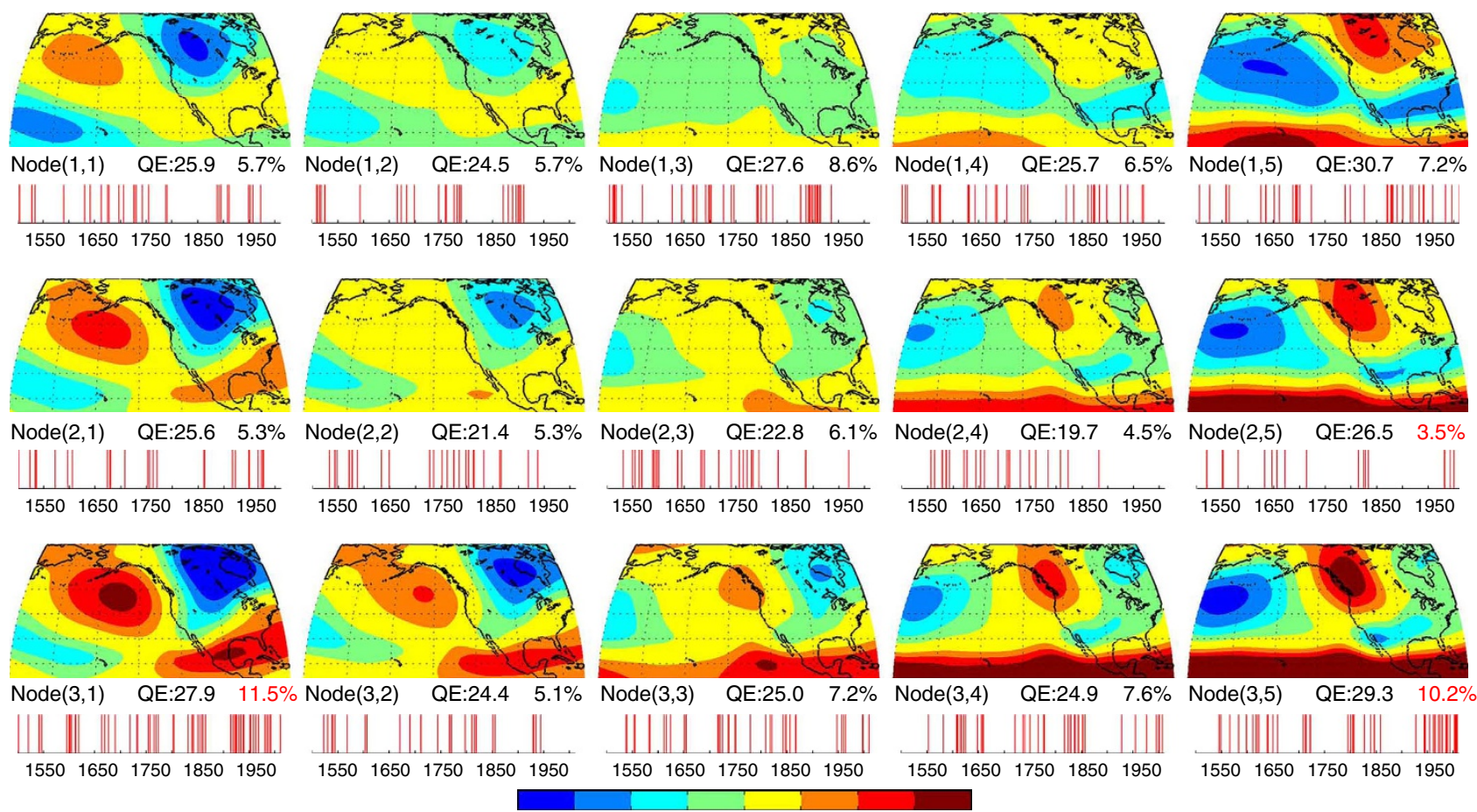

$\begin{array}{llll}-0.8 & -0.6 & -0.4 & -0.2\end{array}$

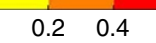

$155016501750 \quad 18501950$

$\begin{array}{lllll}1550 & 1650 & 1750 & 1850 & 1950\end{array}$

Figure 3 | Spatial and temporal distribution of GPH anomalies for AD 1500-2010. Maps show the spatial distribution of standardized GPH anomalies associated with the 15 SOM-classified node patterns. Individual years mapping to each node are shown with a present/absent bar graph time series below each map. Text between maps and time series indicates (left-to-right): nodes numbered as (row, column); average quantization error (QE) between the input years and each master node; and the pattern frequency (\% of years) for the entire period mapping to each node. Frequencies that are above or below the expected range (95\% confidence level; see Methods) are in red.
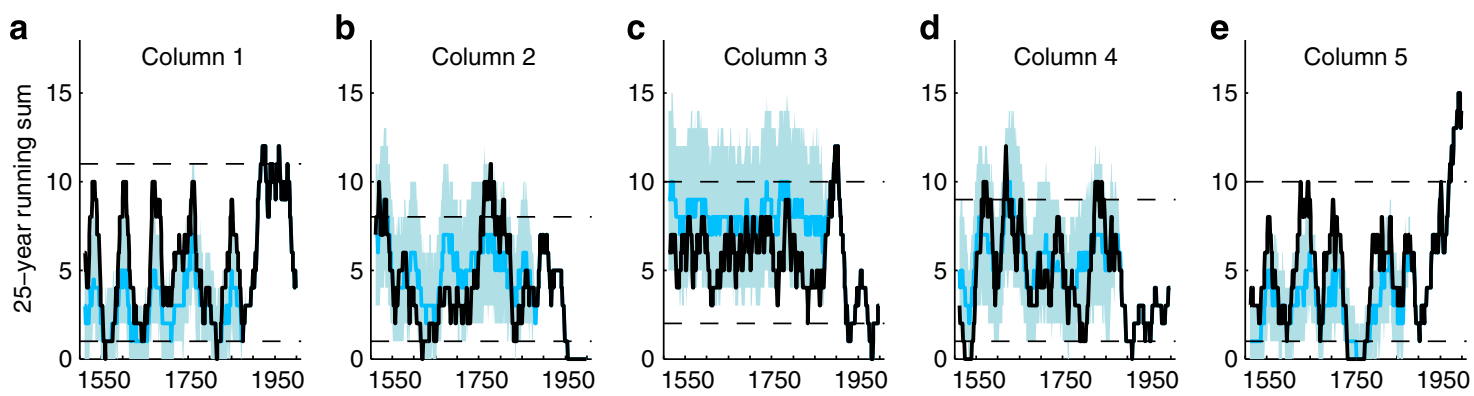

Figure 4 | Persistence of GPH anomaly patterns over time in SOM columns. Number of years within a 25-year moving window assigned to each SOM node (thick black lines) and grouped by SOM columns 1-5 (panels a-e). 95\% confidence intervals (dashed black lines) calculated using Markov Chain simulations. Results based on alternative realizations of the reconstructed GPH field generated using a 1,000-member PPE ensemble are shown with a blue line (median ensemble member) and blue shading (ensemble members falling within the 2.5th-97.5th percentiles).

decadal variability to interannual ENSO mode after 1850 (refs 9,23), with a possible return to decadal variability following the 1976 North Pacific regime shift ${ }^{23}$. The El Niño (column 5) and La Niña (column 1) SOM patterns indicate multidecadal oscillations before the 1900s (Fig. 4).

On the basis of the GPH anomaly patterns (Fig. 3), the striking shift in dominant atmospheric patterns at the end of the LIA (Fig. 5) likely represents a shift from highly meridional to zonal flow. Ice core evidence suggests that the LIA was a period of increased meridional flow ${ }^{28,29}$, and historical records indicate a period of particularly intense meridional circulation in the 1840 s (ref. 30). The climatic shifts at the end of the LIA may represent a weakening of trade winds over the Pacific ${ }^{25}$ and a shift from meridional flow to zonal flow 8,25 . This reconstruction supports previous research ${ }^{31,32}$ suggesting that the majority of the LIA was a period of fluctuating climate conditions rather than a sustained, uniform climate period: before the 1800s, the LIA was characterized by variability across all nodes, although there have been other periods of sustained and persistent GPH anomaly patterns on decadal time scales. Since the early 1900s, there has been a transition back from persistent zonal (row 1) patterns to the dominance of meridional (row 3) patterns (Fig. 5).

Identified shifts in the frequencies and magnitudes of synoptic features can help identify and describe regime shifts in climate and can be useful descriptors of climate variability and change. Understanding 'steps' in climate is important for explaining past events and for future planning, particularly in light of the strong links between atmospheric circulation and hydrologic variability. Evidence from climate models suggests that future regional changes in hydroclimate will depend on multiple drivers of atmospheric moisture transport ${ }^{6}$. Although uncertainties still exist, observations and modelling experiments point to an 
a

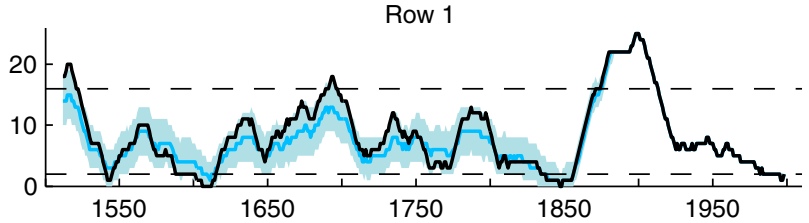

b
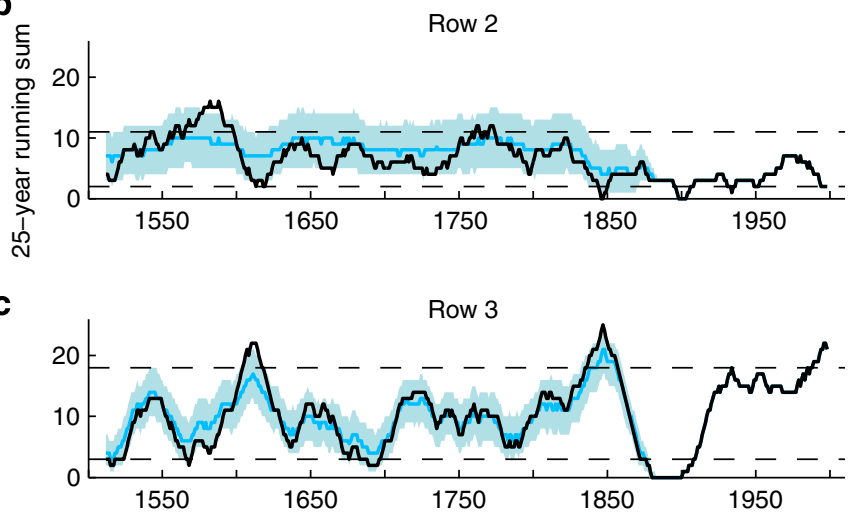

Figure 5 | Persistence of GPH anomaly patterns over time in SOM rows. Number of years within a 25-year moving window assigned to each SOM node (thick black lines) and grouped by SOM rows 1-3 (panels a-c). 95\% confidence intervals (dashed black lines) calculated using Markov Chain simulations. Results based on alternative realizations of the reconstructed GPH field generated using a 1,000-member PPE ensemble are shown with a blue line (median ensemble member) and blue shading (ensemble members falling within the 2.5th-97.5th percentiles).

increase in the frequency and intensity of El Niño, with an associated southward shift and intensification of the subtropical jet stream, an enhanced PNA pattern and an increase in winter and spring storms across much of the U.S. and western Canada ${ }^{33}$, as well as a decrease in zonal flow and weakened westerlies into North America ${ }^{34}$. This reconstruction, which allows dominant atmospheric circulation features of the 20th century to be compared with earlier time periods, indicates that over the past several decades, GPH anomaly patterns have persistently clustered in configurations that mirror observed and modelled climate changes, such as the positive trend in the instrumental PNA index ${ }^{35}$ (Figs 4 and 5). These trends in synoptic circulation patterns have important implications for storminess, snowpack and streamflow in North America ${ }^{33-35}$, and the dominant pressure patterns characterized here will allow for an examination of associated terrestrial climate impact patterns in future research.

\footnotetext{
Methods

Climate field reconstruction model. Raw tree-ring widths within the spatial domain bounded by $10^{\circ} \mathrm{N}$ to $80^{\circ} \mathrm{N}$ latitude and $100^{\circ} \mathrm{E}$ to $60^{\circ} \mathrm{W}$ longitude were obtained from the ITRDB (Fig. 1, www.ncdc.noaa.gov/paleo/treering.html), detrended with a cubic spline two-thirds the length of each individual series, and combined to form site chronologies. This collection was screened to remove duplicate tree-ring series, series with missing data, and series that did not span at least the 1800-1971 time period. Retaining chronologies with an end date of 1971 or later retained $>90 \%$ of the available chronologies while still allowing for a robust 100-year calibration interval. Remaining chronologies underwent significance pre-screening for inclusion into the model: only chronologies correlated at a 0.001 significance level with at least one climate grid cell were retained in the model. Monthly mean $500 \mathrm{hPa}$ GPH values from 20CR2 (ref. 36), spanning $1871-2010$ at a $2.0^{\circ} \times 2.0^{\circ}$ resolution, were converted to cool-season (October-March) anomalies (assigned to the ending year of the season) and used to calibrate the reconstruction model. The spatial domain for the GPH reconstructed grid is $14^{\circ} \mathrm{N}-70^{\circ} \mathrm{N} ; 160^{\circ} \mathrm{E}-70^{\circ} \mathrm{W}$ (Fig. 1).

We used RegEM-ridge ${ }^{11,14}$ to reconstruct cool-season (October-March) $500 \mathrm{hPa}$ GPH anomalies. We assessed model skill using a cross-validation approach wherein 10-year blocks of GPH data were successively withheld and the model was
}

standardized and calibrated using all remaining values, which were then used to estimate the withheld values. This process was repeated through each of the ten decades in the series. To increase independence of each decadal block, the five years of data preceding and following each decade were not used for calibration of the model. Following model validation, both proxy and instrumental data were standardized over the calibration period (1872-1971) for use with the reconstruction model and combined in the input data matrix. We applied a stepwise approach ${ }^{12,13}$ in which the reconstruction was completed by century and the imputed values were incorporated in the data matrix as the RegEM algorithm was applied to successively older segments.

Synoptic climatological analysis. We used the SOM Toolbox (freely available at http://www.cis.hut.fi/somtoolbox) for synoptic climatological analysis of the frequency and persistence of atmospheric pressure patterns and their changes through time. SOM is a neural network approach that treats data as a continuum rather than discrete classes and can be used to objectively identify patterns through the use of an iterative clustering algorithm ${ }^{18}$. The SOM technique requires the user to make an a priori decision concerning the number of nodes $(K)$. Here, we use the false discovery rate technique ${ }^{21,37}$ to determine the value of $K+1$, or the point at which one or more pairs of SOM node patterns become statistically

indistinguishable at the $95 \%$ confidence level. For each tested value of $K$ ( 2 through $25)$, local two-sample $t$-tests are performed at each grid cell between data assigned to every possible pair of nodes. Given the large number of local tests, there is a high probability of 'false discovery' (an incorrect rejection of the null hypothesis). The false discovery rate test corrects for this by examining the distribution of local $P$ values resulting from each of the local $t$-tests ${ }^{37}$ :

$$
p_{\mathrm{FDR}}=\max _{j=1, \ldots, K}\left[p_{j}: p_{j} \leq q(j / K)\right],
$$

where $q$ is the global test level, $p_{j}$ is the $P$-value of the $j$ th local $t$-test and $K$ is the total number of grid cells for which a $t$-test is performed. If the $P$-value of any local $t$-test is smaller than predicted from the uniform distribution of local $P$-values (that is, satisfies the condition in equation (1)), then that test is considered significant and the two node pairs are considered statistically distinguishable 21,37 . Here, the maximum number of statistically distinct GPH patterns used 15 nodes; therefore, we use a 15-node master SOM, which 'self-organized' into a two-dimensional $(3 \times 5)$ grid topology.

Each input value presented to the SOM (in this case, cool-season GPH anomaly fields from 1500 to 2010 ) is assigned to the best-matching node in such a way as to minimize the quantization error, based on the Euclidean distance between the input data and the master $\mathrm{SOM}^{38}$. The probability of any given year mapping to a particular node is $P=1 / N$, where $N$ is the number of nodes. The expected frequency of occurrence $(F)$ of any of the nodes over the entire period ${ }^{38}$ at the $95 \%$ confidence level is given by:

$$
F=p \pm 1.96 \sqrt{\left[\frac{p(1-p)}{n}\right]}
$$

In this study, $P=1 / 15$ (6.7\%); $n=511$ (number of years) and $F=4.5-8.8 \%(95 \%$ confidence interval). We calculated 25 -year running sums of node occurrence grouped by SOM column and row and assessed $95 \%$ confidence intervals using a series of Markov Chain simulations. Markov Chains were constructed by calculating a frequency matrix of transitions from one 'state' (row or column) in year $t$ to another in year $t+1$, and we converted the frequency matrix into a transition probability matrix by dividing each element by its row sum ${ }^{39}$. Twenty-five year synthetic 'chains' were generated by randomly assigning the first year of each chain to one of the three rows (or one of the 5 columns) and then using the transition probability matrix to weight a random assignment of the remaining 24 years based on the 'state' of the previous year. For each chain, the number of occurrences of the rows and columns were calculated, and $95 \%$ confidence levels were defined as any 25 -year period greater than the 97.5 th or less than the 2.5 th percentile of 10,000 synthetic chains ${ }^{21}$.

Pseudoproxy comparison. We evaluated the range of plausible preinstrumental GPH fields that could be generated from the available tree ring and 20CR2 data using a $\mathrm{PPE}^{22}$. One thousand sets of synthetic tree-ring observations (each set consisting of the same number of records and temporal coverage as the actual ITRDB dataset used in this study) were generated based on random draws from the multivariate normal distribution defined by the in-filled data matrix $(\mathrm{GPH}+$ proxy data) and estimated covariance matrix from the final RegEM-ridge model. These pseudoproxies were then substituted into the in-filled data matrix (in place of the tree-ring records), the covariance matrix was re-estimated and this updated covariance matrix was used to impute the missing preinstrumental GPH values using RegEM-ridge ${ }^{11}$, resulting in an ensemble of 1,000 plausible GPH fields covering the preinstrumental period (1500-1871). The annual GPH fields from each PPE were then assigned to nodes in the SOM and 25-year running sums of row and column occurrences were calculated using the same methods as in the previous reconstruction analysis (Figs 4 and 5). We compared yearly SOM row and column assignments from the alternative GPH realizations produced by the PPE ensemble to those of the original GPH reconstruction and evaluated them against random occurrences using equation (2) (Supplementary Tables 1 and 2). 


\section{References}

1. Wise, E. K. Hydroclimatology of the US Intermountain West. Prog. Phys. Geogr. 36, 458-479 (2012).

2. Cayan, D. R., Redmond, K. T. \& Riddle, L. G. ENSO and hydrologic extremes in the western United States. J. Clim. 12, 2881-2893 (1999).

3. McCabe-Glynn, S. et al. Variable North Pacific influence on drought in southwestern North America since AD 854. Nat. Geosci. 6, 617-621 (2013).

4. Wallace, J. M. \& Gutzler, D. S. Teleconnections in the geopotential height field during the Northern Hemisphere winter. Mon. Weather Rev. 109, 784-812 (1981).

5. Granger, O. E. 20th-century climate anomaly patterns over the southwestern United-States. Phys. Geogr. 5, 164-185 (1984).

6. Cook, E. R., Seager, R., Cane, M. A. \& Stahle, D. W. North American drought: reconstructions, causes, and consequences. Earth-Sci. Rev. 81, 93-134 (2007).

7. Fritts, H. C. Reconstructing Large-Scale Climatic Patterns from Tree-Ring Data 286 (University of Arizona Press, 1991).

8. LaMarche, V. Paleoclimatic inferences from long tree-ring records. Science 183, 1043-1048 (1974).

9. Girardin, M. P., Tardif, J., Flannigan, M. D. \& Bergeron, Y. Multicentury reconstruction of the Canadian Drought Code from eastern Canada and its relationship with paleoclimatic indices of atmospheric circulation. Clim. Dynam. 23, 99-115 (2004).

10. Dempster, A., Laird, N. \& Rubin, D. Maximum likelihood from incomplete data via EM algorithm. J. R. Stat. Soc. B Stat. Methodol. 39, 1-38 (1977).

11. Schneider, T. Analysis of incomplete climate data: Estimation of mean values and covariance matrices and imputation of missing values. J. Clim. 14, 853-871 (2001).

12. Mann, M., Rutherford, S., Wahl, E. \& Ammann, C. Testing the fidelity of methods used in proxy-based reconstructions of past climate. J. Clim. 18, 4097-4107 (2005)

13. Rutherford, S. et al. Proxy-based Northern Hemisphere surface temperature reconstructions: sensitivity to method, predictor network, target season, and target domain. J. Clim. 18, 2308-2329 (2005).

14. Dannenberg, M. P. \& Wise, E. K. Performance of climate field reconstruction methods over multiple seasons and climate variables. J. Geophys. Res.-Atmos. 118, 9595-9610 (2013).

15. Pederson, N., Cook, E. R., Jacoby, G. C., Peteet, D. M. \& Griffin, K. L. The influence of winter temperatures on the annual radial growth of six northern range margin tree species. Dendrochronologia 22, 7-29 (2004).

16. Stahle, D. W. et al. Cool- and warm-season precipitation reconstructions over Western New Mexico. I. Clim. 22, 3729-3750 (2009).

17. Vaganov, E. A., Hughes, M. K., Kirdyanov, A., Schweingruber, F. H. \& Silkin, P. P. Influence of snowfall and melt timing on tree growth in subarctic Eurasia. Nature 400, 149-151 (1999).

18. Hewitson, B. \& Crane, R. Self-organizing maps: applications to synoptic climatology. Clim. Res. 22, 13-26 (2002)

19. Reusch, D. B. Nonlinear climatology and paleoclimatology: capturing patterns of variability and change with self-organizing maps. Phys. Chem. Earth 35, 329-340 (2010)

20. Reusch, D., Hewitson, B. \& Alley, R. Towards ice-core-based synoptic reconstructions of west antarctic climate with artificial neural networks. Int. J. Climatol. 25, 581-610 (2005).

21. Johnson, N. C. How many ENSO flavors can we distinguish? J. Clim. 26, 4816-4827 (2013)

22. Smerdon, J. E. Climate models as a test bed for climate reconstruction methods: pseudoproxy experiments. WIREs Clim. Change 3, 63-77 (2012).

23. D'Arrigo, R., Villalba, R. \& Wiles, G. Tree-ring estimates of Pacific decadal climate variability. Clim. Dynam. 18, 219-224 (2001).

24. Zhao, H. \& Moore, G. W. K. Temporal variability in the expression of the Arctic oscillation in the North Pacific. J. Clim. 22, 3110-3126 (2009).
25. Berkelhammer, M., Stott, L., Yoshimura, K., Johnson, K. \& Sinha, A. Synoptic and mesoscale controls on the isotopic composition of precipitation in the western United States. Clim. Dynam. 38, 433-454 (2012).

26. D'Arrigo, R. et al. Tropical-North Pacific climate linkages over the past four centuries. J. Clim. 18, 5253-5265 (2005).

27. Biondi, F., Gershunov, A. \& Cayan, D. R. North Pacific decadal climate variability since 1661. J. Clim. 14, 5-10 (2001).

28. Mayewski, P. A. et al. Greenland ice core signal characteristics - an expanded view of climate-change. J. Geophys. Res.-Atmos. 98, 12839-12847 (1993).

29. O’Brien, S. R. et al. Complexity of Holocene climate as reconstructed from a Greenland ice core. Science 270, 1962-1964 (1995).

30. Mock, C. Historical evidence of a cold, dry summer during 1849 in the northeastern Great-Basin and adjacent Rocky-Mountains. Clim. Change 18, 37-66 (1991).

31. Briffa, K. et al. A 1400-year tree-ring record of summer temperatures in Fennoscandia. Nature 346, 434-439 (1990).

32. Salzer, M. W. \& Kipfmueller, K. F. Reconstructed temperature and precipitation on a millennial timescale from tree-rings in the Southern Colorado Plateau, USA. Clim. Change 70, 465-487 (2005).

33. Basu, S., Zhang, X., Polyakov, I. \& Bhatt, U. North American winter-spring storms: modeling investigation on tropical Pacific sea surface temperature impacts. Geophys. Res. Lett. 40, 5228-5233 (2013).

34. Luce, C. H., Abatzoglou, J. T. \& Holden, Z. A. The missing mountain water: Slower westerlies decrease orographic enhancement in the Pacific Northwest USA. Science 342, 1360-1364 (2013).

35. Abatzoglou, J. T. Influence of the PNA on declining mountain snowpack in the Western United States. Int. J. Climatol. 31, 1135-1142 (2011).

36. Compo, G. P. et al. The twentieth century reanalysis project. Q. J. R. Meteorol. Soc 137, 1-28 (2011).

37. Wilks, D. S. On "field significance" and the false discovery rate. J. Appl. Meteorol. Clim. 45, 1181-1189 (2006).

38. Schuenemann, K. C., Cassano, J. J. \& Finnis, J. Synoptic forcing of precipitation over Greenland: climatology for 1961-99. J. Hydrometeorol. 10, 60-78 (2009).

39. Davis, J. C. Statistics and Data Analysis in Geology (John Wiley \& Sons, 2002).

\section{Acknowledgements}

This research was supported by the National Science Foundation's Paleo Perspectives on Climate Change (P2C2) program through grant AGS-1102757. Thanks to ITRDB contributors for making their data available through the World Data Center for Palaeoclimatology, NOAA Paleoclimatology Program. Tapio Schneider developed the RegEM-ridge program code and the Laboratory of Information and Computer Science, Helsinki University of Technology produced the SOM software.

\section{Author contributions}

E.K.W. designed the study, analysed data and interpreted results and wrote the paper. M.P.D. designed and carried out statistical data analysis, contributed to figure creation and commented on the manuscript.

\section{Additional information}

Supplementary Information accompanies this paper at http://www.nature.com/ naturecommunications

Competing financial interests: The authors declare no competing financial interests

Reprints and permission information is available online at http://www.nature.com/ reprintsandpermissions/

How to cite this article: Wise, E. K. and Dannenberg, M. P. Persistence of pressure patterns over North America and the North Pacific since AD 1500. Nat. Commun. 5:4912 doi: $10.1038 /$ ncomms5912 (2014). 